\title{
INACTIVATION OF CARBOXYPEPTIDASE Y BY MUTATIONAL REMOVAL OF THE PUTATIVE ESSENTIAL HISTIDYL RESIDUE
}

\author{
by
}

\author{
LENE M. BECH and KLAUS BREDDAM \\ Department of Chemistry, Carlsberg Laboratory, \\ Gamle Carlsberg Vej 10, DK-2500 Copenhagen Valby
}

\begin{abstract}
Keywords: Carboxypeptidase, homology, catalytic triad, histidine, cysteine, site-directed mutagenesis
\end{abstract}

\begin{abstract}
Carboxypeptidase $\mathrm{Y}$ is a serine carboxypeptidase assumed to contain a catalytic triad similar to the serine endopeptidases. On the basis of the homology between various serine carboxypeptidases His-397 is suspected to be part of the catalytic triad. To test this it was exchanged with Ala and Arg by site-directed mutagenesis of the cloned PRCl gene. The catalytic efficiency of the mutant enzymes were reduced by a factor of $2 \cdot 10^{4}$ and $7 \cdot 10^{2}$, respectively, confirming the key role of His-397 in catalysis. Treatment of Ala-397-CPD-Y with $\mathbf{H g}^{++}$or $\mathrm{CNBr}$, hence modifying Cys-341 located in the vicinity of the active site abolished the residual activity of the enzyme, indicating an additional involvement of this residue in catalysis.
\end{abstract}

\section{INTRODUCTION}

All the serine endopeptidases, both the "subtilisin-like" and the "trypsin-like", have evolved the same catalytic triad, consisting of Ser, His and Asp, although from two entirely different families of genes (17). A category of carboxypeptidases isolated from fungi, plants and mammals also contains an essential seryl residue and are consequently termed serine carboxypeptidases (8). No three-dimensional structures of such enzymes have yet been determined but it is probable that they also contain a catalytic triad similar to the serine endopeptidases (8). In the serine carboxypeptidase from yeast (CPD-Y) Ser-146 is the essential residue (27) and chloromethylketones, which in the endopeptidases have been demonstrated to specifically modify the essential histidyl residue $(24,26)$, also react with a single histidyl residue in this enzyme and cause inactivation. However, the position of the modified residue has not been identified.

The amino acid sequence of five different serine carboxypeptidases has been determined,

\footnotetext{
Abbreviations: Ala-397-CPD-Y = CPD-Y with an alanyl residue at position 397; Arg-397-CPD-Y = CPD-Y with an arginyl residue at position 397; Bicine $=\mathrm{N}, \mathrm{N}$-bis(2-hydroxyethyl)glycine; CABS-Sepharose $=[\mathrm{N}-(\varepsilon-$ aminocaproyl)-p-aminobenzyl]succinyl-Sepharose 4B; CD = circular dichroism; CPD-Y = carboxypeptidase $Y$; DFP = diisopropylphosphofluoridate; EDTA = ethylenediamine tetraacetic acid, sodium salt; FA = furylacryloyl; GYBS-Sepharose $=[(\mathrm{N}$-glycyl-L-tyrosine $)$-p-azo-benzyl $]$ succinyl-Sepharose 4B; Hepes $=\mathrm{N}$-2-hydroxyethylpiperazine-N'-2-ethanesulfonic acid; HPLC $=$ high performance liquid chromatography; Mes $=2(\mathrm{~N}$-morpholinolethanesulfonic acid; SDS = sodium dodecylsulfate. Abbreviations of amino acids and peptides are according to the guidelines of IUPAC-IUB Commission on Biochemical Nomenclature.
} 


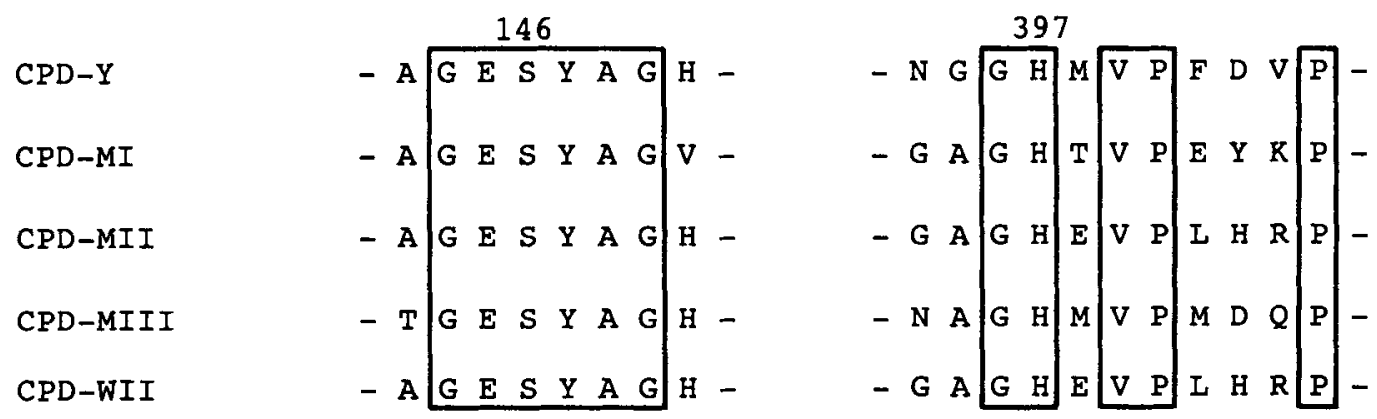

Figure 1. Homology of catalytical important regions of carboxypeptidase Y (7), carboxypeptidases I (28), II (29) and III (30) from malted barley and carboxypeptidase-WII from wheat bran (10). The numbering is that of carboxypeptidase $\mathrm{Y}$.

and they show significant homology $(7,10,28$, $29,30)$. The essential seryl residue is located in a highly conserved region and it is likely that other catalytically important residues similarly are located in well conserved regions. A number of aspartyl residues appear to be conserved, and it is difficult to predict which one might be the essential, while His-397 is the only conserved histidine (Fig. 1). Hence, it is the most probable candidate for a histidyl residue functioning as a general acid/base catalyst in the active site of serine carboxypeptidases. In the present paper this residue is replaced with alanine and arginine, using site-directed mutagenesis of PRC1, the structural gene for CPP-Y, and it is demonstrated that these mutations greatly reduce $\mathrm{k}_{\mathrm{cat}}$ and have only minor effect on $\mathrm{K}_{\mathrm{m}}$.

\section{MATERIALS AND METHODS}

\subsection{Materials}

The plasmid pTSY 3 containing the PRC1 gene, coding for CPD-Y, and Saccharomyces cerevisiae SEY2202 (Mat $\alpha \Delta$ prcl- $\Delta$ l(LEU2) leu2-3 leu2-112 ura3-52 his4-519) were kindly provided by Dr. TOM STEVENS, University of Oregon, USA. The E. coli strain RZ1032 was a generous gift from Dr. Tomas A. KunKel, National Institute of Enviromental Health Sciences, USA. The E. coli strains JM101 (20) and $\mathrm{DH} 5 \alpha$ (14) and the M13mp8-derivative G42 (35) were from house collections. The E. coli strain TG1 was provided in the oligonucleotidedirected in vitro mutagenesis system version 2 kit from Amersham, GB. Restriction endonucleases, T4 polynucleotide kinase, adenosine triphosphate were obtained from Boehringer Mannheim, FRG. HPLC-purified 2' deoxyribonucleic acids were from Pharmacia, Sweden. The Sequenase kit for DNA-sequencing was from United States Biochemical Corp., USA and the Geneclean-kit for purification of DNA fragments was from Bio 101 , USA. $\left[\alpha_{-}{ }^{32} \mathrm{P}\right] \mathrm{dATP}$ $(>800 \mathrm{Ci} / \mathrm{mmol})$ and $\left[\gamma-{ }^{32} \mathrm{P}\right] \mathrm{ATP}(>7000 \mathrm{Ci} /$ mmol) were from New England Nuclear, USA. Trizma base, Mes, Hepes, DTT, agarose and L-amino acids were from Sigma, USA. $\mathrm{HgCl}_{2}$ was from Ferak Berlin, FRG and $\mathrm{CNBr}$ was from Fluka, Switzerland. FA-Phe-OMe was from Bachem, Switzerland and FA-Phe-Leu$\mathrm{OH}$ was prepared as previously described (6). The synthetic oligonucleotides were synthesized on an Applied Biosystem 380 DNA synthesizer according to the procedures provided by the manufacturer. All other reagents and solvents were of analytical purity and obtained from Merck, FRG.

\subsection{Methods}

\subsubsection{Preparation of mutant CPD-Y}

In vitro mutagenesis was performed using a M13mp8 subclone of PRC1 (35). High frequencies of mutants were obtained using either a uracil containing template as described by KunKEL (18) (Arg-397-CPD-Y) or the "oligonucleotide-directed in vitro mutagenesis system version 2" kit from Amersham, based on the 
method of ECKSTEIN and coworkers $(23,25,31$, 32) (Ala-397-CPD-Y).

Autolysis of yeast cells harbouring mutant plasmids and activation of mutant enzymes were carried out as described in ref. 16. The extract was adjusted to $\mathrm{pH} 4.5$ by addition of 1 $\mathrm{M} \mathrm{HCl}$ and applied to a $50 \mathrm{ml}$ GYBS-Sepharose column, equilibrated with $0.02 \mathrm{M} \mathrm{NaAc}, \mathrm{pH} 4.5$. The column was washed with the same buffer until $\mathrm{A}_{280}$ was 0.03 . The enzyme was eluted with $0.1 \mathrm{M} \mathrm{NaH}_{2} \mathrm{PO}_{4}, \mathrm{pH} 7.5$ and the eluate was dialysed against $0.01 \mathrm{M} \mathrm{NaH}_{2} \mathrm{PO}_{4}, \mathrm{pH} 7.0$ and applied to a DE 52 cellulose column $(50 \mathrm{ml})$, equilibrated with the same buffer. After washing of the column with buffer until $A_{280}$ was 0.02 the elution was performed with a gradient from 0 to $0.5 \mathrm{M} \mathrm{NaCl}$ in $0.01 \mathrm{M} \mathrm{NaH}_{2} \mathrm{PO}_{4}, \mathrm{pH} 7.0$ using a total of 9 column volumes. The enzyme eluted at approximately $0.3 \mathrm{M} \mathrm{NaCl}$, and the eluate was dialysed against water and concentrated by ultrafiltration using equipment and YM $10 \mathrm{mem}$ brane from Amicon. The concentration of $\mathrm{NaCl}$ was adjusted to $0.1 \mathrm{M}$ by addition of $5 \mathrm{M} \mathrm{NaCl}$, and the sample was chromatographed on a Sephadex G 100 column $(2.6 \times 87 \mathrm{~cm})$ equilibrated with $0.02 \mathrm{M} \mathrm{NaAc}, 0.1 \mathrm{M} \mathrm{NaCl}, \mathrm{pH} 4.5$. Finally, the enzyme solution was concentrated and dialysed against water. The purification was monitored by Ouchterlony immuno diffusion assays, using $5 \mu \mathrm{l}$ of an antiserum raised against wild type CPD-Y. The diffusions were performed in $1 \%$ agarose gels containing $24.3 \mathrm{mM}$ 5,5-diethyl barbituric acid, $73.2 \mathrm{~mm}$ Tris, 0.8 mM calcium lactate, $2 \mathrm{mM} \mathrm{NaN}_{3}$, $\mathrm{pH} 8.66$ using well diameters of $4 \mathrm{~mm}$. The purity of the resulting enzymes was ascertained by SDS polyacrylamide gel electrophoresis on 10-15\% gradient gels using the Phast system from Pharmacia (34), and by N-terminal sequencing on an Applied Biosystems Model $470 \mathrm{~A}$ gas-phase sequenser using the program provided by the company. The phenylthiohydantoin amino acid derivatives were identified on-line by reverse phase HPLC using equipment from Applied Biosystems.

\subsubsection{Characterization of mutant $C P D-Y$}

The kinetic constants for the hydrolysis of FA-Phe-OMe and FA-Phe-Leu-OH were deter- mined from Lineweaver-Burk plots. Assays were performed in $0.05 \mathrm{M}$ Hepes, $1 \mathrm{~mm}$ EDTA pH 7.5 and 0.05 м Mes, 1 mM EDTA, pH 6.5, respectively, and hydrolysis rates were determined spectrophotometrically at $329-342 \mathrm{~nm}$ and $25{ }^{\circ} \mathrm{C}$, using a Perkin Elmer lambda 7 spectrophotometer. The $\mathrm{pH}$-optimum for the hydrolysis of FA-Phe-OMe was investigated by assays in $25 \mathrm{~mm}$ buffer, $0.1 \mathrm{M} \mathrm{NaCl}, 1 \mathrm{mM}$ EDTA. The following buffers were used: acetic acid, $\mathrm{pH}$ 4-5.23; Mes, pH 5.62-6.72; Hepes, pH 6.757.80; Bicine, $\mathrm{pH}$ 8.28-8.93. Using FA-Phe-OMe as a substrate some background (nonenzymatic) hydrolysis was observed at $\mathrm{pH}$ values above 7 due to long reaction times, and the activities measured were therefore corrected for this spontaneous hydrolysis.

Circular dichroism measurements were made using a Dichrographe II instrument from Roussel Jouan, Paris, using quartz cuvettes with length of $1 \mathrm{~cm}$ or $0.2 \mathrm{~cm}$. The window never exceeded $1 \mathrm{~mm}$. Affinity chromatography on CABS-Sepharose was performed as previously described (6).

\subsubsection{Modifications of mutant enzymes}

Modification of Ala-397-CPD-Y with $\mathrm{HgCl}_{2}$ was performed in $0.05 \mathrm{M}$ Hepes, $\mathrm{pH} 7.5$ using an enzyme concentration of $2.33 \mathrm{mg} / \mathrm{ml}$ and 1.5 equivalents of $\mathrm{Hg}^{++}$. After 15 min incubation at room temperature $10 \mu \mathrm{l}$ of the reaction mixture was assayed against $0.2 \mathrm{mM}$ FA-Phe-Leu-OH, $0.05 \mathrm{M} \mathrm{Mes}, 2.5 \% \mathrm{CH}_{3} \mathrm{OH}, \mathrm{pH} 6.5$. The effect of $\mathrm{KI}$ was tested by including $10^{-3} \mathrm{M} \mathrm{KI}$ in the assay mixture.

Modification of Ala-397-CPD-Y with CNBr was performed in $0.05 \mathrm{M} \mathrm{NaH}_{2} \mathrm{PO}_{4}, 1.5 \mathrm{mM}$ $\mathrm{CNBr}, \mathrm{pH} 7.5$, using an enzyme concentration of $2.33 \mathrm{mg} / \mathrm{ml}$. After two hours of incubation at room temperature $10 \mu \mathrm{l}$ of the reaction mixture was assayed against $0.2 \mathrm{~mm}$ FA-Phe-Leu-OH, 0.05 м Mes, 1 mм EDTA, 2.5\% MeOH, pH 6.5.

\section{RESULTS AND DISCUSSION}

\subsection{Formation of mutant enzymes}

The two mutations His-397 to Arg and His397 to Ala were accomplished in the structural gene for CPD-Y (PRC1) by standard procedures 
Table I. Kinetic parameters for the hydrolysis of FA-Phe-Leu-OH and FA-Phe-OMe with CPD-Y, Arg-397-CPD-Y and Ala-397-CPD-Y.

\begin{tabular}{llcccc}
\hline Substrate & Enzyme & $\begin{array}{l}\mathrm{k}_{\mathrm{cat}} \\
\left(\mathrm{min}^{-1}\right)\end{array}$ & $\begin{array}{l}\mathrm{K}_{\mathrm{m}} \\
(\mathrm{mM})\end{array}$ & $\begin{array}{l}\mathrm{k}_{\mathrm{cat}} / \mathrm{K}_{\mathrm{m}} \\
\left(\mathrm{min}^{-1} \cdot \mathrm{mM}^{-1}\right)\end{array}$ & $\frac{\mathrm{k}_{\mathrm{cat}}(\mathrm{wt})}{\mathrm{k}_{\text {cat }}(\mathrm{mutant})}$ \\
\hline \multirow{3}{*}{ FA-Phe-Leu-OH } & CPD-Y & 4,900 & 0.021 & 230,000 & - \\
& Arg-397-CPD-Y & 7.3 & 0.024 & 300 & $7.7 \cdot 10^{2}$ \\
& Ala-397-CPD-Y & 0.33 & 0.048 & 6.8 & $3.4 \cdot 10^{4}$ \\
& & & & & \\
FA-Phe-OMe & CPD-Y & 11,000 & 0.39 & 28,000 & - \\
& Arg-397-CPD-Y & 15 & 0.36 & 41 & $6.8 \cdot 10^{2}$ \\
& Ala-397-CPD-Y & 1.0 & 0.38 & 2.7 & $1.0 \cdot 10^{4}$ \\
\hline
\end{tabular}

Assay conditions as described in section 2.2.2.

$(18,23,25,31,32)$, and the presence of the mutations were confirmed by chain termination sequencing. The mutated sequences were reintroduced into the E. coli/yeast shuttle-vector pTSY3 replacing the original wild type sequence, and plasmids containing the mutations were used to transform $\mathrm{S}$. cerevisiae strain SEY2202, which contain a deletion in the PRC1-gene. Plasmid bearing yeast cells were grown to saturation in a synthetic medium free of uracil. Mutant enzymes were isolated by affinity chromatography, ion-exchange chromatography and gel filtration as described in section 2.2.1. 7.2 mg Ala-397-CPD-Y and 4.7 mg Arg-397-CPD-Y were isolated from 101 culture medium. The specific activities towards FA-Phe-OMe were $0.004 \mu \mathrm{mol} / \mathrm{min} / \mathrm{mg}$ and $0.13 \mu \mathrm{mol} / \mathrm{min} / \mathrm{mg}$, respectively, compared to $70 \mu \mathrm{mol} / \mathrm{min} / \mathrm{mg}$ for wildtype CPD-Y. SDS-gel electrophoresis and $\mathrm{N}$-terminal sequence determinations demonstrated that the enzyme preparations were homogeneous with molecular weights identical to that of CPD-Y (64.000).

Another mutation, His-397- to Phe, was accomplished too, but upon expression of the mutated gene, no mutant enzyme was produced, as judged by the immuno diffusion assay of the yeast extract.

\subsection{Characterization of mutant enzymes}

The low specific activity of the preparation of mutant enzyme could potentially be due to the presence of a small fraction of native (folded) enzyme with relatively high activity among a population of denatured enzyme molecules.
Therefore, CD spectra of Ala-397-CPD-Y and wild type CPD-Y were recorded between 265 and $210 \mathrm{~nm}$. The spectra were identical, indicating that the secondary structure of the two enzymes are clearly related, and that no significant amount of denatured enzyme is present.

In order to rule out that the residual activities of Ala-397-CPD-Y and Arg-397-CPD-Y are due to contamination of the preparations with wild type CPD-Y the mutant enzymes were rechromatographed on a CABS-Sepharose affinity resin as described in reference 6 . This resin has previously been employed to separate active site modified CPD-Y from unmodified CPD-Y (6): at $\mathrm{pH} 4.8$ both enzymes were bound to the CABS-Sepharose, but only the modified derivative was eluted by an increase of the ionic strength of the buffer; the unmodified enzyme remained bound to the column, but could subsequently be eluted by increasing the $\mathrm{pH}$ to 7.5. Using identical conditions Ala-397-CPD-Y and Arg-397-CPD-Y were bound to this resin, and could subsequently be eluted as active, mutant enzymes by including $0.5 \mathrm{M} \mathrm{NaCl}$ in the buffer. Increasing $\mathrm{pH}$ to $7.5 \mathrm{did}$ not elute any measurable activity, confirming that no wild type enzymes was present.

In modified subtilisin BPN' it has previously been shown that replacement of the catalytic seryl, histidyl or aspartyl residues reduce $\mathrm{k}_{\text {cat }}$ by $1.7 \cdot 10^{6}, 1.6 \cdot 10^{6}$ and $2.6 \cdot 10^{4}$, respectively, while $\mathrm{K}_{\mathrm{m}}$ remains approximately unchanged $(11,12)$. The more pronounced reduction resulting from substitution of Ser-221 and His-64, as compared with Asp-32, are consistent with the central role of these residues in catalysis (17). 
In order to investigate whether the mutant carboxypeptidases behaved similarly they were investigated kinetically using the substrates FAPhe-OMe and FA-Phe-Leu-OH (Table I). Replacement of His-397 with an alanyl residue resulted in reduction of $k_{\text {cat }}$ for both substrates by approximately a factor of $2 \times 10^{4}$, whereas $\mathrm{K}_{\mathrm{m}}$ remained almost unchanged. Introduction of an arginyl residue similarly had no effect on $\mathrm{K}_{\mathrm{m}}$, while $\mathrm{k}_{\text {cat }}$ was decreased by a factor of $7 \times 10^{2}$ (Table I). Thus it is clear that the catalytic apparatus of CPD-Y is drastically damaged by removal of His-397, while the ability of the enzyme to bind the substrate remains essentially unaffected. This is consistent with His- 397 being the essential histidyl residue. The 25 fold higher value of $k_{\text {cat }}$ of Arg-397-CPD-Y as compared with Ala-397-CPD-Y suggest that the arginyl residue to a small extent may replace the histidyl residue as a general acid/base catalyst. It is remarkable that the His $\rightarrow$ Ala mutation in CPD$Y$ has a smaller effect than the corresponding mutation in subtilisin BPN'. This indicates that His-397 in CPD-Y is less essential for catalysis than His-64 of subtilisin BPN', perhaps because other residues of relatively greater importance are involved in catalysis as well.

The $\mathrm{pH}$ profiles for the esterase activity of wild type CPD-Y, Arg-397-CPD-Y and Ala-397CPD-Y towards FA-Phe-OMe are shown in Figure 2. These $\mathrm{pH}$ profiles reflect $\mathrm{k}_{\mathrm{cat}} / \mathrm{K}_{\mathrm{m}}$ since the hydrolysis reactions were carried out at a substrate concentration below $\mathrm{K}_{\mathrm{m}}$. For wild type CPD-Y the activity increases 50 times between pH 4 to 7 , reflecting deprotonation of a group with $\mathrm{pK}_{\mathrm{a}}$ of $5.8-6.0$ - presumably the essential histidyl residue.

The activities of Arg-397-CPD-Y and Ala397-CPD-Y are also influenced by $\mathrm{pH}$, but the increase in activity in the $\mathrm{pH}$ range 4 to 7 is only 10 and 3 times, respectively. This indicates that His-397 is not the only group influencing the $\mathrm{pH}$-profile.

\subsection{Chemical modifications of mutant enzymes}

Studies in this laboratory have shown that $\mathrm{Hg}^{++}$, in the absence of halides, i.e. $\mathrm{Cl}^{-}, \mathrm{Br}^{-}, \mathrm{SCN}^{-}$ and $\mathrm{CN}^{-}$, reacts with Cys-341 and causes complete inactivation of wild type CPD-Y regardless of the nature of the substrate (5). This total lack

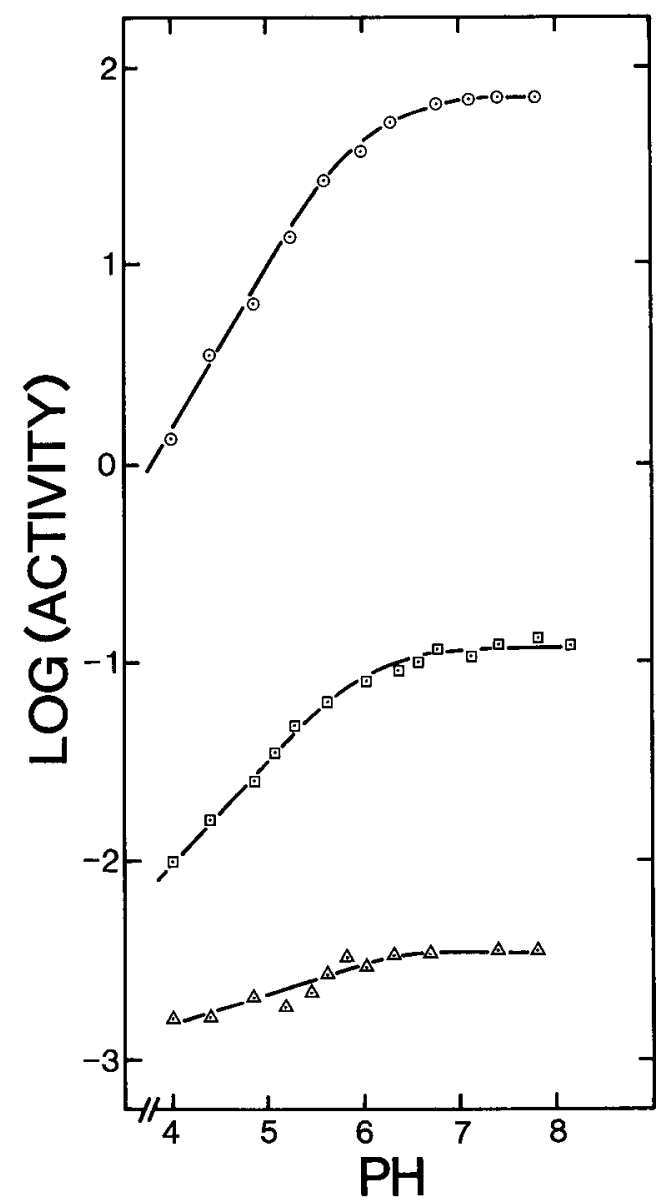

Figure 2. $\mathrm{pH}$ profiles for the hydrolysis of FA-Phe-OMe catalyzed by CPD-Y $(\odot)$, Arg-397-CPD-Y (G) and Ala-397-CPD-Y $(\triangle)$. The ordinate indicates the logarithm to activities in $\mu \mathrm{mol} / \mathrm{min} / \mathrm{mg}$.

of activity of the Cys-341 modified enzyme is possibly due to the mercuric ion forming a S-Hg-X bridge between the sulfhydryl group of Cys-341 and some other amino acid side chain $\mathrm{X}$ capable of forming a rather tight complex with $\mathrm{Hg}^{++}$, e.g. $\mathrm{X}=\mathrm{His}$, Asp or Glu (33). This explanation is supported by the observation that addition of halides, which form tight complexes with $\mathrm{Hg}^{++}(33)$, partially reactivates the enzyme without removing the metal from the enzyme (5) presumably by displacing the side-chain $\mathrm{X}$ from the mercuric ion bound to the sulfhydryl group thus forming a partially active enzyme species. The total loss of activity of the Cys-341 
modified enzyme with no halide present suggest that the side chain $\mathrm{X}$ may be essential for catalysis, and thus the essential histidyl residue is a probable candidate as side chain $X$.

Modification of Ala-397-CPD-Y with 1.5 equivalents of $\mathrm{HgCl}_{2}$, as described in section 2.2.3, abolished more than $95 \%$ of the activity towards FA-Phe-Leu-OH, and addition of $10^{-3} \mathrm{M}$ $\mathrm{KI}$ did not reactivate the enzyme. As addition of $\mathrm{KI}$ to the assay mixture has no detectable effect on the activity of the $\mathrm{Hg}^{++}$derivative, the loss of activity presumably is due to the modification per se - and not to formation of an $-\mathrm{S}-\mathrm{Hg}-\mathrm{X}$ bridge. This indicates that His-397 is the residue partitioning in the bridge in wild type enzyme. Similarly, cyanylation of Cys-341 of Ala-397CPD-Y with $\mathrm{CNBr}$ as previously described for wild type enzyme (9) abolished more than $95 \%$ of the activity towards FA-Phe-Leu-OH.

These results indicate that Cys-341 to a small extent may replace His-397, and thus presumably is responsible for the residual activity of Ala-397-CPD-Y. Assuming that the depletion of activity upon modification of this residue is due mainly to decreases in $\mathrm{k}_{\mathrm{cat}}$, the $\mathrm{Hg}^{++}$- and the cyanylated derivatives both have $k_{\text {cat }}$ values below $0.34 \mathrm{~min}^{-1} \cdot \mathrm{mM}^{-1}$, and this is a reduction by a factor of $7 \cdot 10^{5}$ or more as compared to wild type enzyme. This decrease is of the same order of magnitude as that observed with the $\mathrm{His} \rightarrow \mathrm{Ala}$ mutation of subtilisin (12), and the results are consistent with Cys-341 being involved in catalysis $(1,5,9,36)$. A number of endopeptidases belonging to the subtilisin-like type of enzymes: thermitase from Thermoactinomyces vulgaris $(2,19)$, proteinase $\mathrm{K}$ from Tritirachium album (15), proteinase B from yeast (22) and the yeast $K E X-2$ encoded protein (21) all contain a free cysteinyl residue at the same position in the sequence. The three-dimensional structures of proteinase $\mathrm{K}$ and thermitase have been solved $(3,4,13)$ and in both cases the free cysteinyl residue is burried behind the essential histidyl of the catalytic triad, such that it is practically inaccessible to solvent. $\mathrm{HgCl}_{2}$ is known to react with the conserved cysteinyl residue of these two enzymes and cause inactivation, and thus it is possible that it has a functional resemblance to Cys-341 of CPD-Y.

The results above demonstrate that His- 397 of
CPD-Y is highly involved in catalysis. Chemical modification of Cys-341 of the mutant enzyme Ala-397-CPD-Y almost depletes the activity of the enzyme, indicating that this residue presumably is responsible for the residual activity of Ala-397-CPD-Y.

\section{ACKNOWLEDGEMENTS}

The authors acknowledge Professor MARTIN OTTESEN for critically revising the manuscript. Ms. LILLIAN ABILDGAARD is acknowledged for excellent technical assistance.

\section{REFERENCES}

1. BaI, Y. \& R. HaYashi: Properties of the single sulfhydryl group of carboxypeptidase $Y$. Effects of alkyl and aromatic mercurials on activities toward various synthetic substrates. J. Biol. Chem. 254, 8473-8479 (1979)

2. BaUdyš, M., V. KostKa, G. HaUSDORF, S. FitTKaU \& W.E. HOHNE: Amino acid sequence of the tryptic SH-peptide of thermitase, a thermostable serine proteinase from Thermoactinomyces vulgaris. Relation to the subtilisins. Int. J. Peptide Protein Res. 22, 66-72 (1983)

3. Betzel, C., G.P. Pal, M. Struck, K.D. Jany \& W. SAENGER: Active-site geometry of proteinase $\mathrm{K}$. Crystallographic study of its complex with a dipeptide chloromethyl ketone inhibitor. FEBS Lett. 197, 105-110 (1986)

4. Betzel, C., G.P. Pal \& W. SAenger: Three-dimensional structure of proteinase $\mathrm{K}$ at 0.15 -nm resolution. Eur. J. Biochem. 178, 155-171 (1988)

5. BREDDAM, K.: Modification of the single sulfhydryl group of carboxypeptidase $\mathrm{Y}$ with mercurials. Influence on enzyme specificity. Carlsberg Res. Commun. 48, 9-19 (1983)

6. BREDDAM, K.: Chemically modified carboxypeptidase $\mathrm{Y}$ with increased amidase activity. Carlsberg Res. Commun. 49, 535-554 (1984)

7. BREDDAM, K. \& I. SVENDSEN: Identification of methionyl and cysteinyl residues in the substrate binding site of carboxypeptidase Y. Carlsberg Res. Commun. 49, 639-645 (1984)

8. Breddam, K:: Serine carboxypeptidases. A Review. Carlsberg Res. Commun. 51, 83-128 (1986)

9. BREDDAM, K. \& A. KANSTRUP: Cyanylation of the single sulfhydryl group in carboxypeptidase $Y$ with cyanogen bromide. Carlsberg Res. Commun. 52, 65-71 (1987)

10. BReddam, K., S.B. Sørensen \& I. SVendSen: Primary structure and enzymatic properties of car- 
boxypeptidase II from wheat bran. Carlsberg Res. Commun. 52, 297-311 (1987)

11. Carter, P. \& J.A. Wells: Engineering enzyme specificity by "substrate-assisted catalysis". Science 237, 394-399 (1987)

12. CARTER, P. \& J.A. Wells: Dissecting the catalytic triad of a serine protease. Nature 332, 564-568 (1988)

13. Dauter, Z., C. Betzel, W.E. Höhne, M. Ingelman \& K.S. WILSON: Crystal structure of a complex between thermitase from Thermoactinomyces $\mathrm{vul}$ garis and the leech inhibitor eglin. FEBS Lett. 236, 171-178 (1988)

14. Hanahan, D.: Techniques for transformation of E. coli. In: DNA Cloning. A Pratical Approach. D.M. Glover (ed.), Vol. 1, IRL Oxford, 109-135 (1985)

15. JANY, K.-D., G. LEDERER \& B. MAYER: Amino acid sequence of proteinase $\mathrm{K}$ from the mold $T r i$ tirachium album Limber. Proteinase K - a subtilisin-related enzyme with disulfide bonds. FEBS Lett. 199, 139-144 (1986)

16. JOHANSEN, J, T., K. BREDDAM \& M. OTtesen: Isolation of carboxypeptidase $\mathrm{Y}$ by affinity chromatography. Carlsberg Res. Commun. 41, 1-14 (1976)

17. KRAUT, J.: Serine proteases: structure and mechanism of catalysis. Ann. Rev. Biochem. 46, 331-358 (1977)

18. KUNKEL, T.A.: Rapid and efficient site-specific mutagenesis without phenotypic selection. Proc. Natl. Acad. Sci. USA 82, 488-492 (1985)

19. Meloun, B., M. Baudyś, V. KostKa, G. Hausdorf, C. FROMMEL \& W.E. HOHNE: Complete primary structure of thermitase from Thermoactinomyces vulgaris and its structural features related to the subtilisin-type proteinases. FEBS Lett. 183, 195200 (1985)

20. MEssinG, J.: A multi-purpose cloning system based on the single-stranded DNA bacteriophage M13. Recombinant DNA Tech. Bull., NIH publication No. 79-99, 2, 43-48 (1979)

21. Mizuno, K., T. Nakamura, T. Ohshima, S TANAKa \& H. MatSUO: Yeast KEX2 gene encodes an endopeptidase homologous to subtilisin-like serine proteases. Biochem. Biophys. Res. Commun. 156, 246-254 (1988)

22. Moenle, C.M., R. Tizard, S.K. Lemmon, J. Smart \& E. JONEs: Protease B of the lysosomelike vacuole of the yeast Saccharomyces cerevisiae is homologous to the subtilisin family of serine proteases. Mol. Cell. Biol. 7, 4390-4399 (1987)

23. NAKAMAYE, K.L. \& F. ECKSTEIN: Inhibition of restriction endonuclease Nci 1 cleavage by phosphorothioate groups and its application to oligonucleotide-directed mutagenesis. Nucl. Acid Res. 14, 9679-9698 (1986)
24. ONG, E.B., E. Shaw \& G. Schoellman: An active center histidine peptide of $\alpha$-chymotrypsin. J. Am. Chem. Soc. 86, 1271-1272 (1964)

25. SAYERS, J.R., W. SCHMidT \& F. ECKSTEIN: 5'3'exonucleases in phosphorothioate-based oligonucleotide-directed mutagenesis. Nucl. Acid Res. 16, 791-802 (1988)

26. ShaW, E., M. MARes-Guia \& W. COHEN: Evidence for an active-center histidine in trypsin through use of a specific reagent, 1-chloro-3-tosylamido-7amino-2-heptanone, the chloromethyl ketone derived from $\mathrm{N}_{\mathrm{a}}$-tosyl-L-lysine. Biochemistry 4 , 2219-2224 (1965)

27. SVEndSen, I., B.M. MaRtin, T. Viswanatha \& J.T. JOHANSEN: Amino acid sequence of carboxypeptidase Y. II. Peptides from enzymatic cleavages. Carlsberg Res. Commun. 47, 15-27 (1982)

28. Sørensen, S.B., K. Breddam\& I. Svendsen: Primary structure of carboxypeptidase I from malted barley. Carlsberg Res. Commun. 51, 475-485 (1986)

29. SøRENSEN, S.B., I. SVENDSEN \& K. BREDDAM: Primary structure of carboxypeptidase II from maited barley. Carlsberg Res. Commun. 52, 285-295 (1987)

30. SøRENSEn, S.B., I.SVENDSEN \& K. BREDDAM: Primary structure of carboxypeptidase III from malted barley. Manuscript in preparation

31. TAYLOR, J.W., J. OTT \& F. ECKSTEIN: The rapid generation of oligonucleotide-directed mutations at high frequency using phosphorothioate-modified DNA. Nucl. Acids Res. 13, 8765-8785 (1985)

32. TAYlor, J.W., W. SChmidt, R. Cosstick, A. OKRUSZEK \& F. ECKSTEIN: The use of phosphorothioate modified DNA in restriction enzyme reactions to prepare nicked DNA. Nucl. Acids Res. 13, 8749-8764 (1985)

33. WEBB, J.L.: Mercurials. In: Enzyme and Metabolic Inhibitors. Academic Press. Vol. II, 729-983 (1963)

34. Weber, K.., J.R. PRINGLE \& M. OsBORNE: Measurement of molecular weights by electrophoresis on SDS-acrylamide-gel. Methods Enzymol. 26, 3-27 (1972)

35. WINTHER, J.R., M.C. KIELLAND-BRANDT \& K. BREDDAM: Increased hydrophobicity of the $S_{j}$ binding site in carboxypeptidase $Y$ obtained by site-directed mutagenesis. Carlsberg Res. Commun. 50, 273-284 (1985)

36. WINTHER, J.R. \& K. BREDDAM: The free sulfhydryl group (Cys 341) of carboxypeptidase Y: Functional effects of mutational substitutions. Carlsberg Res. Commun. 52, 263-273 (1987)

Accepted by H. KLENOW 